\title{
Knowing and Designing: Understanding Information Use in Open Source Design Through the Lens of Information Archetypes
}

\author{
Kevin Lumbard \\ University of Nebraska at \\ Omaha \\ klumbard@unomaha.edu
}

\author{
Ammar Abid \\ University of Nebraska at \\ Omaha \\ aabid@unomaha.edu
}

\author{
Christine Toh \\ University of Nebraska at \\ Omaha \\ ctoh@unomaha.edu
}

\author{
Matt Germonprez \\ University of Nebraska at \\ Omaha \\ germonprez@gmail.com
}

\begin{abstract}
The early phases of the product design process are crucial to the success of design outcomes. While information utilized during idea development has tremendous potential to impact the final design, there is a lack of understanding about the types of information utilized in industry, making it challenging to develop and teach methodologies that support the design of competitive products. As a first step in understanding this process, this study focuses on developing a framework of Information Archetypes utilized by designers in industry. This was accomplished through in-depth analysis of qualitative interviews with large software engineering companies. The results reveal two archetypes of information utilized by decision-makers within these companies during the development of new products and services. The findings of this study allow for future research that investigates the role of information during the product design process.
\end{abstract}

\section{Introduction}

In today's constantly shifting technology landscape, companies are required to generate innovative solutions quickly and effectively to respond to rapid changes in customer needs, new market opportunities, and emerging technologies [57]. This link between innovation and long-term economic success has been widely acknowledged [3], leading to substantial investments in increasing the innovation capabilities of the United States [25]. Therefore, research focus has been on improving the practice and education of design to meet these growing needs.

Within the field of design, the availability of information is crucial to the success of many stages of the design process since design is viewed as an 'information-centric' enterprise [28, 33]. In fact, researchers have argued that the very act of design is the process of transforming information gathered from the environment to actionable knowledge that can be used to make decisions during the design process [44].
While information has traditionally been highly valued during the product design process, the increasing availability of information due to recent information technology trends are transforming information from a highly coveted advantage to a freely accessible commodity for innovation [33]. As an example, significant changes have taken place in industry with the inclusion and integration of open source software into commercial design processes $[13,18,23]$. These studies show that new access to information has the potential to play a crucial role in shaping the field of design and creativity, but it is still not clear how designers in industry are navigating these abundant streams of information during design. This knowledge gap poses challenges to design research and education since we do not yet know how to best leverage these information sources to increase the quality of design outcomes, or how to best train the next generation of designers to operate effectively in this environment.

This exploratory study develops a typological framework for understanding the information utilized by designers in industry. This was accomplished through in-depth analysis of qualitative interviews with designers from software engineering organizations, engaged with open source communities. In addition to a preliminary typological framework, the results of this study are used to advance and empirically test the types of information present during design decision making.

\subsection{Design in Open Source Communities}

The investigation of open source communities has a long research history, set against lenses of innovation [8], fluidity [24] and social structures [14]. Such research has focused on the internal dynamics of open source communities, considering complex questions of how social networks are comprised and evolve within these communities [24], evident governance structures [52], and the nature of information exchange within these communities [36]. While the investigation of the internal dynamics of open source communities is critical in advancing our understanding of open source communities, new structures for engagement with open 
source communities reveal open source moving beyond its egalitarian roots and becoming a critical component of for-profit design streams [34].

Since the early 2000 s, open source communities have served as a key component of for-profit organizational design streams. Companies such as Hewlett Packard, Tesla, and Google leverage open source communities for a variety of reasons including lowered internal development costs and increased corporate product time-to-market. In these arrangements, corporations engage with open source communities because they provide a platform where shared and non-differentiating practices or technologies (those practices or technologies not unique to an organization's design stream) can be collaborated on. Namely, for-profit companies engage with open source communities because they provide low-cost solutions to universally shared problems [8].

Open source has become such a pervasive part of how for-profit corporations perform software development, non-profit and trade organizations, such as the Linux Foundation, have grown to house these corporately important projects [56]. Foundations provide brokerage services to help manage and stabilize open source communities for reasons of long term health and sustainability [22]. If an open source community that is being leveraged as part of a corporate design stream becomes stagnant or unsupported, any benefit of engagement becomes hindered. Foundations exist, in large part, to ensure that communities with broad interest and reach remain stable over time for all involved [23, 56]. In these complicated contexts of communities, corporations, and foundations, design becomes a dynamic and responsive activity that is subject to the many engaged members, environmental contexts, and stabilizing structures [23], where each participant can engage with the community in ways that are relevant to their own interests.

While prior research has identified many information sources that designers draw from [27], the purpose of this study is to investigate the types of information utilized when making design decisions in software development. Specifically, this is explored in the context of corporate engagement with open source communities. Design occurs in varied contexts and exploration of this variation can lead to robust design theories. Furthermore, open source design has become a critical part of corporate innovation and is a structured and regularized in line with internal corporate design practices $[12,19,23]$ making it a necessary context for design research. In this paper, we explore design as rooted in the Information Archetypes that exist in these dynamic design environments. Lakhani and Von Hippel [36] premise that information is an exchange between suppliers and providers. We too believe this and further explore the depth to which information exists within these complex design environments.

\subsection{Information in Design Decision-making}

Researchers and practitioners recognize the importance of information in influencing the direction of the design process. From the information-gathering stage of customer needs assessment to the design embodiment and realization stages, the success of design hinges on the identification of key pieces of information that will help designers develop products and services that successfully addresses design goals [45]. Furthermore, fundamental research has argued that the acquisition and transformation of information are integral to the design and development of creative ideas [55]. However, research has also shown that some forms of information can be detrimental to the creative process by fixating the designer on a set of ideas or concepts regardless of their potential for innovation or success [32]. These contrasting findings highlight the complex nature of information availability, quality, and timing on design creativity, and necessitate an in-depth exploration of what information impacts the design process as it occurs in practice.

Researchers have begun to explore information usage, organization, and impact in design practice to shed light on design creation and decision-making in industry. These studies highlight the varied characteristics, dimensions, and forms of information that is utilized during the design process. For example, studies that have explored the process in which new products are developed in industry have identified external sources of information, such as new technologies, as key drivers of decision-making during the design process [40]. Similarly, studies into the conceptual design phase in the product design industry have shown that teams tend to focus on the end goals of the design, such as the needs of the customer, as the key source of information for design activities [41].

Protocol studies investigating expert designers also show that designers frequently engage with abstract levels of information while problem-solving in order to maximize the effectiveness of solution finding [4]. Other research has revealed that design exemplars, both within and beyond the domain of the design, and using varied forms of representation, are used by professionals in the creative design process [27]. Such research in software engineering has explored the use of cross-cutting features to streamline the development process [38]. Finally, research has focused on effectively utilizing guidelines across entire product families to analyze commonality across domains and increase the effectiveness of product design [54].

While these studies highlight the wide variety of information used during the design process, there is a 
lack of a comprehensive framework for characterizing information impacting the design process. In addition, the types of information evident during the design process in corporate engagement with open source artifacts are still largely unknown. Prior work in this area has identified that compliance information defines communal design obligations [53], historical information defines design trajectories [30], and shared information defines cooperative design activities [34]. Building from this work, our study develops evident information within design processes by advancing a framework for characterizing the types of information used during the design process found in the context of corporate engagement with open source communities.

\subsection{Research Objectives}

The objective of this research is to develop a framework of design information dimensions and archetypes. While research studies have individually explored important types of information relevant to design practice in industry, none have synthesized this knowledge into a typological framework for capturing information used by designers to make decisions during the design process. With this framework, systematic and substantive research on how design information influences the process of innovation can be advanced. Thus, this study is a first step in building this framework by analyzing in-depth interviews with designers from large software development companies regarding their engagement with open source communities during design. Content analysis was performed on the interviews to identify design constructs used to make decisions during design, as understood from prior literature. From this, five dimensions of information and two preliminary information archetypes were identified. A discussion of the implications and contributions of this research are then presented.

\section{Methodology}

To advance an Information Archetype framework of design information, we explored select interviews conducted as part of an ongoing six-year qualitative field study exploring corporate engagement with open source communities. During the field study, we conducted over 100 interviews and three focus groups with managers and developers, participated in ten Linux Foundation conferences, directly participated in open source communities, and contributed to both open source technologies and standards. The interview sample was identified through the Linux Foundation, community engagement, and snowball sampling

As engaged field researchers, we treated ourselves as an "instrument of knowing" (p. 3, [47] in [17]), providing grounded interpretation of design information. Deep field engagement allowed us to generate significantly more data and understand that data in more detail than if we simply acted as external observers. This allowed us to build from our own reflective experiences, and as a sense-making experience, to understand the cognitive, social, and technological structures of the field, constructing a "system of meaning within which our experience is embedded" [17]. It is through this lens of engaged field research, that the data was analyzed to identify the dimensions and archetypes of information used to make decisions during the design process.

\subsection{Participants}

This exploratory study examined a subset of the collected field study data. The data used in this study consisted of interviews and focus groups conducted across ten organizations (six of which are Fortune 1000 companies) actively engaged in open source development. These ten organizations were chosen for this study since the interviews conducted with these companies specifically focused on artifacts derived from open source software, and they were mature open source contributing organizations who would be able to draw from rich experiences regarding their design process. In total, the interviews included 17 developers and managers ( 2 females, 15 male). As part of their employment, these individuals were tasked and remunerated to directly participate with open source communities in the design and development of both corporate and communal outcomes.

\subsection{Qualitative Data Coding Procedure}

The data consisted of 11 one-hour interviews with individuals from nine organizations and one three-hour focus group interview with an additional organization, totaling 242 pages of transcribed text. During the study, participants were asked semi-structured interview questions aimed at assessing their process of engaging with open source communities during design activities. The questions covered areas such as information gathering, contributions, risk, and organizational structure. Sample interview questions include:

What factors do you believe drive a company to utilize Linux when building products?

Does participation in the Linux community require new forms of organizational structure and process management?

Is corporate participation with the Linux community driven by a need for the technology, or are there other reasons to participate? 
To capture the various forms of information utilized by designers, a framework of Information Archetypes was developed. The typological approach to building theories was used, as discussed by Doty and Glick [16]. According to this framework, a theoretical understanding of applied phenomena can be captured through the development of dimensions and archetypes that build on the dimensions. The typological form and theory building using typologies offers several advantages over other forms. It allows "specification of non-linear relationships of constructs", it provides "a mechanism for incorporating the holistic principle of enquiry into organizational research," and it "incorporates equifinality in theories" [16]. This approach of using typologies to build theory has been applied in disciplines such as organizational science and social psychology (see [5, 7, 43, 46, 48]). In design, Dorst and Overveld [15] developed typologies of design practice that describe the type of activities typically conducted in the product design process. From this work, we advance a typological approach to describe the types of information utilized in design and provide a theoretical framework to describe how these types of information are related.

To build theory based on typologies, Doty and Glick [16] first recommend that dimensions are built that capture specific aspects of an entity. Next, archetypes are understood as complex phenomena that are described in terms of multiple dimensions. Thus, each ideal-type "represents a unique combination of dimensions used to describe the set of ideal types" [16]. Archetypes, or ideal types, represent a pure conceptualization of entities and are expected to be very rare, or non-existent in empirical data. Through the act of developing ideal types, a deeper understanding of the observed space is obtained, and a theory-based framework of the phenomena can be used for further research. Doty and Glick [16], further state that typologies are complex theories that hypothesize relationships between ideal types that can be subjected to rigorous testing. Following this approach, we utilize a multi-step process of first developing an initial typological framework that can then be validated and empirically tested using follow up studies. Thus, this preliminary study focuses this initial stage of building information archetypes from prior literature and does not attempt to make predictions of design outcomes. More research is needed to validate this framework and test the predictive power of such a model on empirical data. In the current study, this approach of building typologies was used to analyze the interviews and build a theoretical framework of information use in design.

We first developed a handbook of design information dimensions through a review of design literature. The handbook was further refined through a series of five one-hour exploratory analyses of interview transcripts with all four authors. The dimensions were the result of literature review, discussions, preliminary exploratory analysis of the transcribed interviews, and reflective experiences gained during the field study. These dimensions of design information led to the creation of an Information Dimensions Handbook containing descriptions and examples of each dimension. The handbook is available at: https://github.com/InformationArchetypes/Dimensions.

Following this analysis and construction of the handbook, the first and second authors analyzed the 242 pages of transcribed text using the principles of content analysis [42] to deductively apply the dimensions to the interview data using NVivo v.11 [49]. Over the course of the coding process, the first and second authors met 12 times, for a total of over 33 hours. During these meetings, a deep shared understanding of the design dimensions was built collaboratively.

To ensure inter-coder reliability, the first and second authors first independently coded one transcript using the handbook and met to discuss the results and build shared mental models about these design dimensions. This recursive process was repeated for all remaining transcripts. During this process, the first and second author aligned understanding of dimensions, edited the handbook to merge or refine dimensions, and reached agreement on specific sections of interview text to code. These sections of text were organized into blocks approximately four to five sentences in length.

The first and second authors then independently coded the agreed upon blocks of text across the remaining pages of transcribed interview text. The interrater reliability (Cohen's Kappa) of all five dimensions showed an acceptable level agreement for an exploratory study [39] as seen in Table 1. After the independent coding sessions were complete, consensus across all dimensions was reached through pair coding and discussion of disagreements.

\section{Table 1: Inter-reliability statistics for the five} information dimensions and levels.

\begin{tabular}{|c|c|c|}
\hline Dimension & Level & Cohen's Kappa \\
\hline \multirow{2}{*}{1 Information Source } & External & 0.60 \\
\hline & Internal & 0.75 \\
\hline \multirow{2}{*}{2 Abstraction of Information } & Abstract & 0.83 \\
\hline & Concrete & 0.52 \\
\hline \multirow{2}{*}{3 Generality of Information } & Cross-Cutting & 0.71 \\
\hline & Domain Specific & 0.59 \\
\hline \multirow{2}{*}{4 Effectuation of Information } & Casual & 0.61 \\
\hline & Effectual & 0.63 \\
\hline \multirow{3}{*}{5 Representation of Information } & Asynchronous & 0.74 \\
\hline & Synchronous & 0.84 \\
\hline & Average & 0.68 \\
\hline
\end{tabular}


We next detail these dimensions and highlight their linguistic proximity to each other. Hence, we provide a view into the evident information dimensions as well as their role in an Information Archetype framework.

\section{Information Dimensions}

Our research sought to investigate the dimensions of information used by designers during the decisionmaking process in design. Specifically, content analysis was conducted on the interview transcripts to uncover information dimensions and their corresponding levels. In all, five main dimensions with two corresponding levels each were identified (Figure 1).

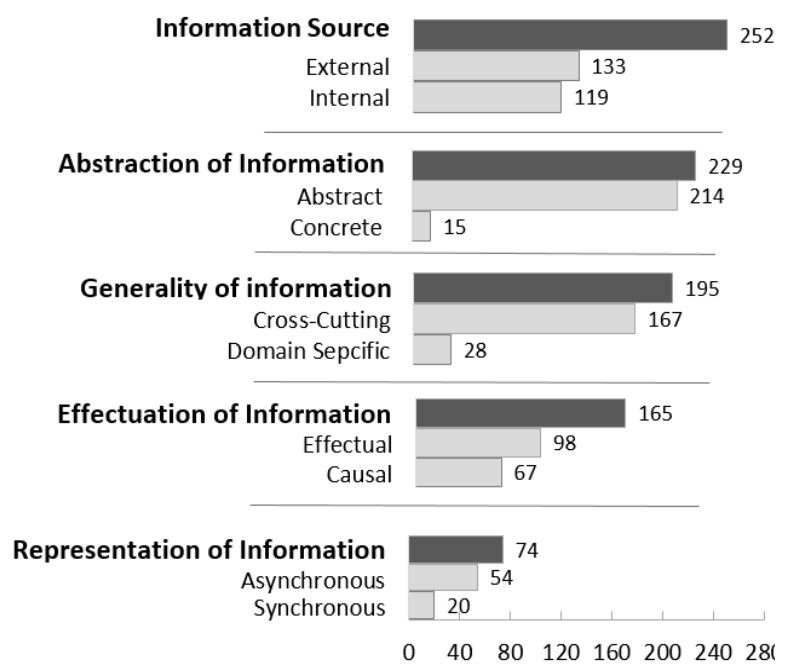

Figure 1: Times each information dimension (dark gray), and levels (light gray), were found in the interviews.

Following, we present descriptions and examples of dimensions and their levels as found in the interviews.

\subsection{Information Source}

The first dimension is Information Source $(\mathrm{f}=252)$. This dimension focuses on exploring the origin of information with respect to the individual or organization that generated the idea of the design. Thus, this dimension was broken down into two levels: Internal $(\mathrm{f}=119)$ and External $(\mathrm{f}=133)$ information. Specifically, information coming from an individual or their organization was considered internal. One participant described utilizing internal software resources in a project: "Well, with [open source OS] we've had to build it from scratch because it's brand new, so there is a lot of code in there that was originally proprietary... We do start a lot of projects where some of the code is internal, and we think that we get some advantage from making it open".
Information originating from outside the organization during the information gathering or idea generation phase is considered as external. One participant described obtaining software from outside the organization during their design process: "We took the Linux kernel code and we decided that we were going to make all of these modifications to it for the [our 64bit processor] we were working on". This result is supported by prior work that has shown that information relevant to the design process is obtained from a variety of sources, both internal and external. For example, new products in industry are routinely developed using external sources of information, such as new technologies or trends [31]. Designers rely on external sources of information to guide and inform their design efforts and ensure competitiveness in increasingly crowded markets. Interestingly, researchers have also shown that designers' own cognition is equally critical to the development and assessment of design ideas. Seminal work on design cognition has shown that design experts rely heavily on past experiences and pattern recognition in design problems to generate the most innovative and effective solutions to problems [2].

\subsection{Abstraction of Information}

The second dimension is Abstraction of Information $(\mathrm{f}=229)$. This dimension was defined as the level of detail included in the information and the extent to which the information dealt with concepts versus discrete reallife events. This dimension was divided into two levels: Abstract $(\mathrm{f}=214)$ and Concrete $(\mathrm{f}=15)$ information. Information that was theoretical in nature, or did not deal with specific instances in time were considered abstract. One participant described hypothetical and generalized information about their design process: "And some of the code is directly related to the work that [our company] does and the hardware drivers. But we also do a lot of work that helps us in a more indirect way. We have a guy who's done a whole bunch of power optimizations in the Linux kernel... whose job is completely dedicated to that and to making things faster and more efficient and a few other things really around power consumption".

Concrete information dealt with specific details and events. A participant described information related to a specific product: "If we're doing massive audio processing, low latency audio processing requires a couple gigaflops of $C P U$ and we're talking low latency in terms of 166 microseconds, it's not going to happen in a user task, at least not with [our product]". As seen in Figure 2, most information found in this dimension was considered abstract. This result is supported by prior work that shows that designers frequently engage with abstract levels of information while problem-solving in order to maximize the effectiveness of solution finding [4]. In a sense, abstract levels of information are more 
easily recalled in contrast with specific instances or examples, and serve to help the designer cope with high levels of complexity in design problems [29]. However, researchers have also uncovered evidence that the ability to use concrete representations can aid in decision-making when there is a high level of uncertainty in the design [10].

\subsection{Generality of Information}

The third dimension is Generality of Information $(\mathrm{f}=195)$. Two levels were developed for this dimension: Domain Specific $(\mathrm{f}=28)$ and Cross-cutting $(\mathrm{f}=167)$ information. This dimension describes the generalizability of the information to other design tasks and projects. Domain specific means information used is directly related to the product domain. One participant described software design in a specific software domain: "To provide a graphics driver for Linux, we chose to leverage the same graphics driver code base - the core code base that's used on all the other platforms. So, the core of our code for [our open driver] for kernel-level support... is common across [multiple platforms]".

Cross-cutting refers to information used in the design process that is relevant across many design domains. A participant described common processes used for projects across multiple domains: "Translation is big for a lot of projects. You know, it's written in English, and people everywhere else want to use it. And so, translating is a good way to contribute to projects". The results showed that designers in open source development use both cross-cutting and domain specific information in the design process, however, they are primarily concerned with cross-cutting types of information. Prior literature supports designers' usage of cross-cutting features to streamline the development process [38] as well as the use of information and heuristics to apply generality across instances and to improve the design process [54].

\subsection{Effectuation of Information}

The fourth dimension is Effectuation of Information $(\mathrm{f}=165)$. This dimension was broken down into two levels: Effectual $(\mathrm{f}=98)$ and Causal $(\mathrm{f}=67)$ information. Effectuation of information explores the varied thinking styles of designers in addressing the design problem. Prior work in entrepreneurship judgment has shown that there are two distinct approaches to solving a problem: using existing resources to generate effective solutions to problems found in the market (effectuation), or starting with identifying a specific market need and working towards addressing that need using any resources necessary, whether available or not (causation) [50]. Information was coded as effectual if it described how design goals are identified and pursued based on available means. One participant described leveraging existing open source resources to reduce development burden: "What we get is $90 \%$ of the system, so [we] do less than 10\% of the work. We then leverage that investment to provide client value. If we were doing Linux on our own, we would have to do that other 90\% instead of doing other things for our clients and stockholders".

Causal was defined as information that focused on addressing a specific goal using any kind of resource, immediately available or not. One participant discussed making design decisions based solely on customer needs: "It had to be based on circumstances that were involved and you just needed to solve that customer's mission. If that was the piece of code you needed, you'll come up with the right way to do it". The results show that designers utilize both effectual and causal modes of thinking. While prior work argues that effectual thinking tends to lead to successful creative endeavors [26], and are used frequently by experts [50], others argue that the integration of both effectual and causal thinking are lead to strategic decision-making [1].

\subsection{Representation of Information}

The final dimension is Representation of Information $(\mathrm{f}=74)$. This dimension was broken down into two levels: Asynchronous $(\mathrm{f}=54)$ and Synchronous $(\mathrm{f}=20)$ information. Representation of Information revolves around the form of communication used to deliver information during the design process. Asynchronous is defined as information acquired using virtual tools such as email, chat, blogs, bug trackers, digital documents, and comments in code. One participant described using online collaboration tools in the design process: "We've had some requests for people to use software that they found in a blog posting. And without a license attached to it, you just didn't know where it came from".

Synchronous is defined as information acquired inperson through meetings and conferences or using realtime communication tools such as phone calls and video conferences. One participant discussed using face-toface meetings to share information: "We invite a bunch of people who are working on key components of the Linux kernel and we bring them in and we talk and tell them exactly what [our company] is doing, why, and what we'd like to see in the kernel and how we can work better together to do that". These results are echoed by prior research that has identified the channels through which designers obtain information during the design process [27]. In researching the design space, designers may share example products with their peers through email, with a link to the example and a brief description of the product [27], while other research has shown that 
direct communication in the early stages of design is crucial to the creativity of the final solution [6].

\section{Information Archetypes}

Once the key dimensions of information were identified in this study, information archetypes were developed to capture the main groups of information found in design decision-making in open-source engagement. In advancing a typological framework on Information Archetypes, preliminary analyses were conducted on the results of the information dimensions found in the interviews. A frequency matrix was created to identify frequent overlap where dimensions tended to occur concurrently in the data. We identify these overlaps as our initial Information Archetypes. We observed many relationships between dimensions but for the purposes of this study, we explicate Information Archetypes as combinations of information dimensions that occur at least $70 \%$ of the time on the same coding block (4-5 sentences). Figure 2 shows that while 70\% was chosen as the cut-off point, relationships among other dimensions were observed less frequently. The two Information Archetypes observed at $70 \%$ were Domain Specific \& Abstract (Engaging Differences) and Concrete \& Cross-cutting (Managing Complexity).

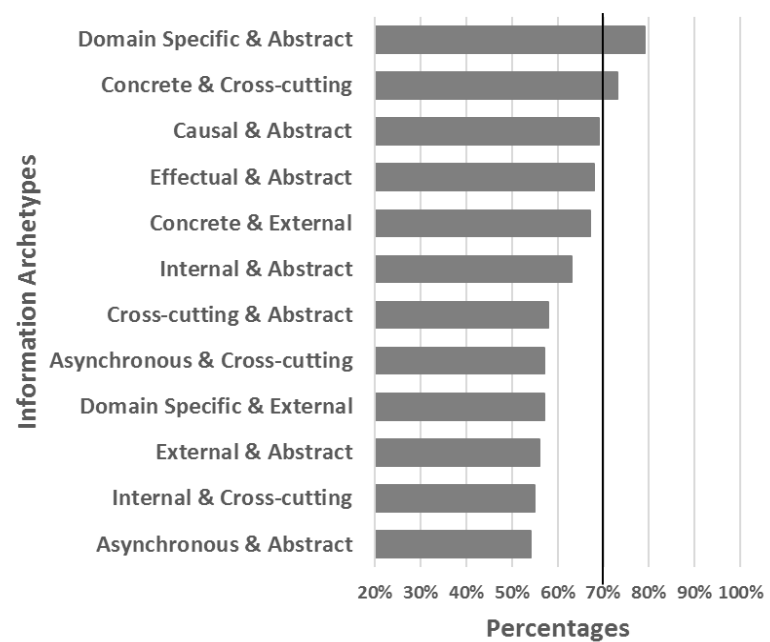

Figure 2: The top 12 co-occurring dimensions representing information archetypes

\subsection{Engaging Differences: Domain Specific \& Abstract}

The Engaging Differences archetype was identified as information that was both Domain Specific and Abstract. Specifically, of the 28 times that Domain Specific information was identified in the interviews, Abstract information was present $79 \%$ of the time. We further observed tertiary relationships between the Engaging Differences archetype and the
External (50\%), Internal (36\%), Effectual (27\%), Causal $(23 \%)$ and Asynchronous (9\%) dimensions. However, for the purposes of this study, relationships between three information dimensions was not explored due to the lower number of co-occurring 3-way relationships.

The Engaging Differences archetype was observed when comparing systems to one another in relation to product differentiation. The archetype is represented in conversations about the process of identifying and adding missing components to projects by comparing them to proprietary systems: "At the moment, [we have] a project to improve the Linux kernel and what we'll be doing is to look at [our internal operating system] and compare Linux and say, 'Well, those are the things that [our internal operating system] has which Linux is not for the moment"'. The archetype was also present as participants discuss differentiation strategies, whether the product has "a bit of differentiation in terms of features", or if "there's not much point in differentiating in them".

Supporting this archetype, a wealth of research has explored the importance of strategically focusing resources on product differentiation. Specifically, product differentiation has been used for developing effective product families [35] and increasing customer satisfaction [51]. For profit corporations often conserve resources for competitively differentiated products while utilizing open source communities for the development of non-differentiating technologies [37].

\subsection{Managing Complexity: Concrete \& Cross- cutting}

The Managing Complexity archetype was identified as information that was both Concrete and Crosscutting. Of the 15 times that concrete information was identified, cross-cutting information was present $73 \%$ of the time. Thus, this was considered an information archetype. We further observed tertiary relationships between the Managing Complexity archetype and the External (64\%), Effectual (27\%), and Asynchronous (9\%) dimensions.

The Managing Complexity archetype is often related to scaling systems, compliance, and optimizing shared resources. The archetype is represented in conversations about scaling standard open source systems to improve efficiency: "We integrated the first Linux based supercomputer for a large public organization... To be able to do that you had to do some changes in the operating system to make that possible because you were running Linux on much larger systems than had been used before". The archetype is further represented as a participant discusses open source license compliance and community standards: "We forked Memcached and Memcached is licensed under 
BSD so like we have to - we generally go Apache 2.0 by default but if we're working with a community, we'll go with what the community generally uses as kind of our baseline position policy".

Supporting this archetype, the strength of open source software development is often attributed to the speed of development, reliability, portability, and scalability of the resulting software [11]. Prior research has shown that compliance information defines community design obligations [53]. Finally, research in design theory has explored product complexity and variability by identifying and verifying cross-cutting features of systems [38] and proposing methodologies and architectures for managing and designing these complex systems [20].

\section{Impetus for Design Research}

This study advances information archetypes for understanding the types of information utilized by designers in the design process. This was addressed by observing designers engaged in open source communities and exploring information usage in design. The main design contributions of this study are:

- Seeing information dimensions characterize design.

- Identifying emerging information archetypes between information dimensions as used in design.

- Recognizing and revealing the intricacies of design in complex environments.

As we identified dimensions of information utilized in the design decision-making process, we further recognize design as more than a means-ends activity. Design is a dynamic activity that relies on variable sources of information and that this information can be used to value design that protects strategic interests, fosters communities, and leverages open source goods. Our results advance design theory by revealing that abstract and cross-cutting information was heavily used in open source development. This finding is supported by prior literature that has also explicated similar issues [2, 38]. In contrast, other concepts highlighted in previous research, such as the use of analogies in design [21], were not identified. This points to potential differences in information use when engaging design in different contexts.

Further, we found design to support a distinct pattern of information co-occurrence that represent our initial information archetypes: Engaging Differences and Managing Complexity. These findings have implications for understanding design, identifying potentially meaningful patterns of information in design. This finding extends prior design theory work on information types $[9,27]$ by advancing a framework that structures these information types.

\section{Limitations and Future Work}

While this exploratory study was successful in advancing a typological framework, there are several important limitations. First, this was an exploratory study examining a limited number of interviews that were not originally focused on information use in design. In response, the results of this study have been used to create interview questions on information and design for a study that is now in-progress. The follow-up study is expanding the analysis of information use using a larger corpus of interviews with designers and developers. Second, the interviews analyzed in this study were conducted with high-level managers and supervising developers involved in large-scale corporate environments. Therefore, it is not clear how these archetypes translate to different levels of personnel. To advance the typology, the focused interview questions will be directed towards designers and developers in varying organizational roles and organization sizes engaged with open source communities. Third, there are limitations to the use of the typological framework for theory building [16] that apply. Specifically, the "ideal types" identified through empirical work may not necessarily predict any outcomes and may not be constant in different research contexts. Therefore, further work is needed to investigate the use of these information archetypes in design activities and discussions, beyond retrospective interviews.

\section{Conclusions}

In this work, we advance a typological framework of information archetypes. By understanding the types of information utilized during open source design and their relation to one another, we contribute to design theory, design practice, and open source software communities. This was accomplished through in-depth analysis of interviews with large software engineering companies actively engaged in open source development, and analysis using the principles of content analysis. The result of this exploratory study revealed five information dimensions and two preliminary information archetypes utilized by decision-makers within corporate-open source engagements. Further research focused on the validation and predictive power of these preliminary archetypes can provide tools for research aimed at enhancing technical innovation and improving the training of the next generation of designers.

\section{Acknowledgements}

This project received funding through the National Science Foundation's Virtual Organizations as Sociotechnical Systems and the Innovation and 
Organizational Sciences Programs [VOSS-IOS: 1122642].

\section{References}

[1] Agogue, M., M. Lundqvist, and K.W. Middleton, "Mindful deviation through combining causation and effectuation: A design theory-based study of technology entrepreneurship", Creativity and Innovation Management 24(4), 2015, pp. 629-644.

[2] Akin, Ö., "Necessary conditions for design expertise and creativity", Design Studies 11(2), 1990, pp. 107-113.

[3] Ayağ, Z., and R.G. Özdemir, "A hybrid approach to concept selection through fuzzy analytic network process", Computers \& Industrial Engineering 56(1), 2009, pp. 368379.

[4] Ball, L.J., J. St. BT Evans, I. Dennis, and T.C. Ormerod, "Problem-solving strategies and expertise in engineering design”, Thinking \& Reasoning 3(4), 1997, pp. 247-270.

[5] Brandtzæg, P.B., "Towards a unified Media-User Typology (MUT): A meta-analysis and review of the research literature on media-user typologies", Computers in Human Behavior 26(5), 2010, pp. 940-956.

[6] Brown, V.R., and P.B. Paulus, "Making group brainstorming more effective: Recommendations from an associative memory perspective", Current Directions in Psychological Science 11(6), 2002, pp. 208-212.

[7] Büchel, F., E. Humprecht, L. Castro-Herrero, S. Engesser, and M. Brüggemann, "Building empirical typologies with QCA: Toward a classification of media systems", The International Journal of Press/Politics 21(2), 2016, pp. 209-232.

[8] Chesbrough, H.W., Open innovation: The new imperative for creating and profiting from technology, Harvard Business Press, 2006.

[9] Christensen, B.T., and C.D. Schunn, "The relationship of analogical distance to analogical function and pre-inventive structure: The case of engineering design", Memory \& cognition 35(1), 2007, pp. 29-38.

[10] Christensen, B.T., and C.D. Schunn, "The role and impact of mental simulation in design", Applied cognitive psychology 23(3), 2009, pp. 327-344.

[11] Crowston, K., and B. Scozzi, "Open source software projects as virtual organisations: competency rallying for software development", IEE Proceedings - Software 149(1), 2002, pp. 3-17.

[12] Dahlander, L., "Penguin in a new suit: A tale of how de novo entrants emerged to harness free and open source software communities", Industrial and Corporate Change 16(5), 2007, pp. 913-943.

[13] Dahlander, L., and M.G. Magnusson, "Relationships between open source software companies and communities: Observations from Nordic firms", Research Policy 34(4), 2005, pp. 481-493.
[14] Daniel, S., R. Agarwal, and K.J. Stewart, "The effects of diversity in global, distributed collectives: A study of open source project success", Information Systems Research 24(2), 2013, pp. 312-333.

[15] Dorst, K., and K. van Overveld, "Typologies of design practice", Philosophy of technology and engineering sciences 9, 2009, pp. 455 .

[16] Doty, D.H., and W.H. Glick, "Typologies as a unique form of theory building: Toward improved understanding and modeling", Academy of management review 19(2), 1994, pp. 230-251.

[17] Dourish, P., "Reading and interpreting ethnography", In J. Olson and W. Kellogg, eds., Ways of Knowing in HCI. Springer, 2014, 1-23.

[18] Feller, J., Perspectives on free and open source software, MIT press, Cambridge, MA, 2005.

[19] Fitzgerald, B., "The transformation of open source software", MIS Quarterly 30(3), 2006, pp. 587-598.

[20] Galster, M., U. Zdun, D. Weyns, et al., "Variability and Complexity in Software Design: Towards a Research Agenda", SIGSOFT Softw. Eng. Notes 41(6), 2017, pp. 2730 .

[21] Gentner, D., and A.B. Markman, "Structure Mapping in Analogy and Similarity", American Psychologist 52, 1997, pp. $45-56$.

[22] Germonprez, M., J.P. Allen, B. Warner, J. Hill, and G. McClements, "Open source communities of competitors", Interactions 20(6), 2013, pp. 54-59.

[23] Germonprez, M., J.E. Kendall, K.E. Kendall, L. Mathiassen, B. Young, and B. Warner, "A Theory of Responsive Design: A Field Study of Corporate Engagement with Open Source Communities", Information Systems Research 28(1), 2016, pp. 64-83.

[24] Goggins, S.P., and G. Valetto, "Assessing the Structural Fluidity of Virtual Organizations and Its Effects", In Socioinformatics-The Social Impact of Interactions between Humans and IT. Springer, Heidelberg, 2014, 121-137.

[25] Gonzalez, H.B., and J.J. Kuenzi, "Science, technology, engineering, and mathematics (STEM) education: A primer", Congressional Research Service, Library of Congress (2012).

[26] Harms, R., and H. Schiele, “Antecedents and consequences of effectuation and causation in the international new venture creation process", Journal of international entrepreneurship 10(2), 2012, pp. 95-116.

[27] Herring, S.R., C.-C. Chang, J. Krantzler, and B.P. Bailey, "Getting inspired!: understanding how and why examples are used in creative design practice", Proceedings of the SIGCHI Conference on Human Factors in Computing Systems, ACM (2009), 87-96.

[28] Herring, S.R., B.R. Jones, and B.P. Bailey, "Idea generation techniques among creative professionals", System Sciences, 2009. HICSS'09. 42nd Hawaii International Conference on, IEEE (2009), 1-10. 
[29] Hoover, S.P., J.R. Rinderle, and S. Finger, "Models and abstractions in design", Design Studies 12(4), 1991, pp. 237245.

[30] Hovorka, D.S., M. Germonprez, and M. Levy, "Design history: exploring corporate communities", At the Vanguard of Design Science: First Impressions and Early Findings from Ongoing Research Research-in-Progress Papers and Poster Presentations from the 10th International Conference, DESRIST 2015., (2015).

[31] Hunter, S.T., C. Thoroughgood, and S. Cassidy, "Leading innovative teams. In G. S. Ligon's (Chair), Human Resource Management Interventions for Innovation", Symposium at the 24th annual Society for Industrial and Organizational Psychology Conference (2010).

[32] Jansson, D.G., and S.M. Smith, "Design fixation", Design studies 12(1), 1991, pp. 3-11.

[33] Kalay, Y.E., "The impact of information technology on design methods, products and practices", Design studies 27(3), 2006, pp. 357-380.

[34] Kelty, C.M., Two bits: The cultural significance of free software, Duke University Press, 2008.

[35] Kumar, D., W. Chen, and T.W. Simpson, “A marketdriven approach to product family design", International Journal of Production Research 47(1), 2009, pp. 71-104.

[36] Lakhani, K.R., and E. Von Hippel, "How open source software works: 'free' user-to-user assistance", Research policy 32(6), 2003, pp. 923-943.

[37] Levy, M., and M. Germonprez, "Is it egalitarianism or enterprise strategy? Exploring a new method of innovation in open source", Americas Conference on Information Systems (2015).

[38] Li, H., S. Krishnamurthi, and K. Fisler, "Verifying cross-cutting features as open systems", ACM SIGSOFT Software Engineering Notes 27(6), 2002, pp. 89-98.

[39] Lombard, M., J. Snyder-Duch, and C.C. Bracken, "Content analysis in mass communication: assessment and reporting of intercoder reliability", Human Communication Research 28(4), 2002, pp. 587-604.

[40] López-Mesa, B., and N. Bylund, "A study of the use of concept selection methods from inside a company", Research in Engineering Design 22(1), 2011, pp. 7-27.

[41] Maurer, C., and J. Widmann, "Conceptual design theory in education versus practice in industry: a comparison between Germany and the United States", ASME 2012 international design engineering technical conferences and computers and information in engineering conference, Chicago, Illinois, (2012), 12-15.

[42] Mayring, P., "Qualitative Content Analysis", In U. Flick, E. Von Kardoff and I. Steinke, eds., A companion to qualitative research. Sage, Great Britain, 2004, 266-269.

[43] Mintzberg, H., "The structuring of organizations", In Readings in Strategic Management. Springer, 1989, 322352.
[44] Mistree, F., W.F. Smith, B.A. Bras, J.K. Allen, and D. Muster, "Decision-based design: a contemporary paradigm for ship design", Transactions, Society of Naval Architects and Marine Engineers 98, 1990, pp. 565-597.

[45] Ogot, M., and G. Okudan-Kremer, Engineering design: a practical guide, Trafford Publishing, 2004.

[46] O’Raghallaigh, P., D. Sammon, and C. Murphy, "Theory-building using Typologies-A Worked Example of Building a Typology of Knowledge Activities for Innovation", Proceedings of the 2010 conference on Bridging the Socio-technical Gap in Decision Support Systems: Challenges for the Next Decade, IOS Press (2010), 371-382.

[47] Ortner, S.B., Anthropology and social theory: Culture, power, and the acting subject, Duke University Press, 2006.

[48] Paré, G., M.-C. Trudel, M. Jaana, and S. Kitsiou, "Synthesizing information systems knowledge: A typology of literature reviews", Information \& Management 52(2), 2015, pp. 183-199.

[49] QSR, NVivo Qualitative Data Analysis Software, QSR International Pty Ltd, 2012.

[50] Sarasvathy, S.D., "Causation and effectuation: Toward a theoretical shift from economic inevitability to entrepreneurial contingency", Academy of management Review 26(2), 2001, pp. 243-263.

[51] Sauerwein, E., F. Bailom, K. Matzler, and H.H. Hinterhuber, "The Kano model: How to delight your customers", International Working Seminar on Production Economics, (1996), 313-327.

[52] Shah, S.K., "Motivation, Governance, and the Viability of Hybrid Forms in Open Source Software Development", Management Science 52(7), 2006, pp. 1000-1014.

[53] Stewart, K.J., A.P. Ammeter, and L.M. Maruping, "Impacts of license choice and organizational sponsorship on user interest and development activity in open source software projects", Information Systems Research 17(2), 2006, pp. 126-144.

[54] Thevenot, H.J., and T.W. Simpson, "Commonality indices for product family design: a detailed comparison", Journal of Engineering Design 17(2), 2006, pp. 99-119.

[55] Wallas, G., The art of thought, Harcourt Brace, New York, 1926.

[56] West, J., and S. O'mahony, "The Role of Participation Architecture in Growing Sponsored Open Source Communities", Industry and Innovation 15(2), 2008, pp. 145168.

[57] Yazdankhah, A., and M. Fathalipourbonab, "Optimizing New Product Concept Selection Decisions Considering Life Cycle Design Attributes", International Journal of Modeling and Optimization 4(2), 2014, pp. 146. 